\title{
PERFIL DEL TERAPUETA OCUPACIONAL DE LA UNIVERSIDAD NACIONAL
}

\author{
Por: ALEIDA FERNÁNDEZ, T.O., \\ $\mathrm{Mg}$. en Desarrollo Educativo y Social \\ Coordinadora Académica \\ Carrera de Terapia Ocupacional
}

En primer lugar deseo agradecer a la Junta Directiva de la Asociación esta oportunidad para dirigirme a tan selecto grupo de colegas. Me han solicitado hablar sobre el perfil profesional del Terapeuta Ocupacional que se forma en la Universidad Nacional de Colombia. Todo lo que se desarrolla a continuación se soporta en el Documento de Renovación Curricular de 1.992, y el trabajo del Comité de Acreditación del Departamento de Terapia de la Universidad Nacional.

Para hablar del perfil es necesario contextualizar y hacer algo de historia. En la Universidad Nacional surge en 1966 el primer programa de formación del país. Inicialmente la propuesta fue de 6 semestres de formación a nivel técnico. Posteriormente, hacia 1975, con la primera reforma curricular y con la inclusión de un trabajo investigativo como prerrequisito de grado, se inicia la etapa de la licenciatura. Luego con algunas reorganizaciones al plan de estudio a nueve semestres y atendiendo a la legislación pertinente se otorga el título de Terapeuta Ocupacional.

A finales de los años ochenta, un grupo de docentes se empieza a reunir para navegar en las aguas del conocimiento, a reflexionar sobre el currículo vigente y con un arduo trabajo que coincide con los grandes avances profesionales mundiales logrados en esta época, surge la actual reforma curricular, que se articuló con una macroreforma que emprendió la Universidad en todos sus programas profesionales, y que ha sido la más amplia y significativa de los últimos tiempos.

De esta reforma ya contamos con la primera cohorte; el primer grupo egreśa este año. Hago alusión a esto porque lo que "sembramos hoy es la 
cosecha del mañana", es decir que "el estudiante que formamos hoy es el Terapeuta del próximo milenio".

Ahora quisiera destacar algunas de las directrices fundamentales que se incluyen en el actual programa curricular para así poder vislumbrar el perfil profesional de nuestro egresado en las próximas décadas. Ellas son:

Coherencia Conceptual Interna

- Relación con el Contexto Nacional

- Flexibilización

- Profundización

\section{COHERENCIA CONCEPTUAL INTERNA}

Es decir que la organización del conocimiento tiene un eje central y éste en la Universidad Nacional es el "estudio del Desempeño Ocupacional del ser humano en todo su ciclo vital". Para ello se cuenta con asignaturas nucleares que abordan, o al menos lo intentan, las teorías propias de la Terapia Ocupacional. Y digo intentan, porque el avance es lento y aunque existen teorías propias de la profesión, la mayoría son generadas en contextos culturales y geográficos diferentes al nuestro y requieren para su apropiación procesos de reflexión, sistematización e investigación aún incipientes.

Lo importante de esta organización y este esfuerzo es que va permitiendo desde el primer semestre la configuración de la identidad profesional en el estudiante, que se enriquece a lo largo de todo el proceso académico con múltiples experiencias curriculares.

\section{RELACIÓN CON EL CONTEXTO NACIONAL}

Esta directriz curricular es un deber y un reto para la carrera en la Universidad Nacional. Y no es nada fácil pues se trata de asegurar la recontextualización y la actualización permanente de la Terapia Ocupacional frente a los problemas del país que son de nuestra competencia, teniendo en cuenta tanto la realidad nacional como la evolución del conocimiento propio de la profesión. 


\section{FLEXIBILIZACIÓN}

La Universidad ofrecer cursos de contexto y asignaturas electivas que según los intereses particulares del estudiante pueden ser cursados durante la carrera en cualquiera de las Facultades. El propósito de estos cursos es contribuir a definir y fortalecer el perfil del estudiante en su área de elección. Por ejemplo, un estudiante interesado en el área sociolaboral, puede cursar en la Facultad de Ciencias Económicas: Gestión de Recursos Humanos, en la Facultad de Artes: Ergonomía, en la Facultad de Enfermería: Salud y Condiciones de Trabajo, entre otras.

\section{PROFUNDIZACIÓN}

Aunque hace parte del componente flexible, es importante hacer una consideración especial y es que en la profundización se abordan temas de actualidad con reflexión, análisis y argumentación en áreas de competencia profesional. En la actualidad las líneas de profundización: "Desempeño Ocupacional Funcional" y "Desempeñ்o Ocupacional y Disfunción", plantean problemas que cuentan con espacios de discusión, asesoría y el conocimiento pertinente para afrontar la situación en el área de interés.

Sin embargo, deseo señalar que todo este proceso no ha sido nada sencillo. Por ejemplo, en la flexibilización, aun tenemos problemas por falta de cupos en asignaturas de contexto y electivas, cruces de horarios e incluso prerrequisitos que limitan en muchos casos la elección del estudiante. En el caso de las líneas de profundización, existen factores como el limitado tiempo docente y la falta de material bibliográfico actualizado, que están lentificando su consolidación.

Para resumir, en la actualidad contamos con la primera cohorte del nuevo programa curricular. Los esfuerzos se dirigen a que las directrices mencionadas: coherencia interna, relación con el contexto nacional, flexibilización y profundización, se conviertan en una red de significados que confluyan en un estudiante cada vez mejor preparado para la vida profesional y el cambiante mundo laboral que le espera. Por esto se siguen adelantando procesos de evaluación y revisión curricular entre directivas, estudiantes y docentes que permitan dilucidar los problemas existentes y plantear soluciones viables para cumplir con la misión que el Comité de Acreditación 
ha formulado para la carrera de Terapia Ocupacional de finales del siglo $\mathrm{XX}$ :

"Formar con perspectiva global, ciudadanos éticos: Que comprendan la realidad multicultural colombiana de las capacidades y discapacidades del desempeño ocupacional. Que sean capaces de formular una política sobre discapacidad, prevención y rehabilitación y gerenciar y suministrar servicios ocupacionales estratégicos de alta calidad, eficiencia y cobertura".

Es decir "Lograr el reconocimiento social de la Terapia Ocupacional", que es tarea de docentes, estudiantes, universidades, profesionales y por supuesto de la Asociación Colombiana de Terapia Ocupacional". 


\section{REFERENCIAS}

- TRUJILlO, A., ALVAREZ, L., TORRES, M., ZAPATA, M.V. Propuesta de renovación curricular de la Carrera de Terapia Ocupacional. Universidad Nacional de Colombia. Santafé de Bogotá, Agosto de 1992.

- COMITÉ DE AUTOEVALUACIÓN Y ACREDITACIÓN PRO. GRAMAS CURRICULARES DE TERAPIA FÍSICA, TERAPIA OCUPACIONAL Y FONOAUDIOLOGÍA. Procesos de Acreditación: MISIÓN POSIBLE. Santafé de Bogotá, D.C. Septiembre de 1997. 


\section{FE DE ERRATAS}

En la edición pasada de la Revista Ocupación Humana Correspondiente al Vol. 7 No 2. De 1997.

El artículo de la Escuela Colombiana de Rehabilitación, no se encontraba autoria alguna.

Se aclara que este fué realizado por la..T.O. Elvia Cuartas, decana de dicha facultad en ese momento. 